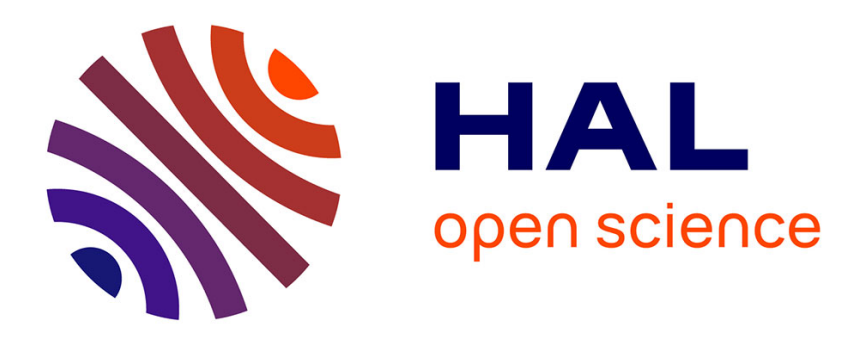

\title{
Gas formation during reaction sintering of titanium aluminides
}

\author{
G. Leitner, K. Jaenicke-Rössler
}

\section{To cite this version:}

G. Leitner, K. Jaenicke-Rössler. Gas formation during reaction sintering of titanium aluminides. Journal de Physique IV Proceedings, 1993, 03 (C7), pp.C7-403-C7-410. 10.1051/jp4:1993763 jpa00252182

\section{HAL Id: jpa-00252182 https://hal.science/jpa-00252182}

Submitted on 1 Jan 1993

HAL is a multi-disciplinary open access archive for the deposit and dissemination of scientific research documents, whether they are published or not. The documents may come from teaching and research institutions in France or abroad, or from public or private research centers.
L'archive ouverte pluridisciplinaire HAL, est destinée au dépôt et à la diffusion de documents scientifiques de niveau recherche, publiés ou non, émanant des établissements d'enseignement et de recherche français ou étrangers, des laboratoires publics ou privés. 


\title{
Gas formation during reaction sintering of titanium aluminides
}

\author{
G. LEITNER and K. JAENICKE-RÖSSLER \\ Fraunhofer Institution for Ceramic Technologies and Sintering Materials, IKTS Dresden, Germany
}

\begin{abstract}
Titanium aluminides are attractive materials not only for aviation and space research but also for application in automotive engines.

Reaction sintering of titanium aluminides involves considerable swelling during phase formation; the reason for this effect has not been understood until now. A strong increase of porosity is connected with this swelling of the samples, which must be avoided by using expensive HIP techniques.

The influence of gas reactions on the swclling is investigated by mass-spectrometric analysis of the gases produced during reaction sintering. By means of simultaneous measurements of mass change (thermobalance), enthalpy change (DTA) and gas production (quadrupole mass-spectrometer) in dependence on temperature significant information on the course of the reaction sintering process is found.
\end{abstract}

Espescially it is possible to determine the generation of hydrogen and gaseous water during the heating process and to correlate them to the swelling effects. From these results conclusions may be drawn for an optimization of the sintering parameters during reaction sintering of titanium aluminides.

\section{Introduction}

Titanium aluminides, especially $\gamma$-TiAl, are attractive materials not only for aviation and space research but also for applications in automotive engines. Favourable mechanical properties at high temperatures and the low density of these alloys are interesting for such applications, but on the other hand, the high brittleness of these intermetallics and the high costs for overcoming this problem have been the most important difficulties on the way to industrial-scale production of formed parts up to now.

One way to form titanium aluminides is based on the powder-metallurgical route [1-2]. A mixture of titanium and aluminium elementary powders is compacted and then formed to rods by extrusion. During the ensuing sintering treatment the components react with each other, forming intermetallic phases. Reaction sintering of titanium aluminides involves partly considerable swelling effects during phase formation [3-5]. These effects largely depend on the test conditions (such as heating-up rate). The increase in volume can amount to as much as $50 \%$. This increased porosity must be eliminated by an ensuing HIP treatment, which requires additional encapsulation owing to the open pores. The increase in volume has its roots mainly in the development of the structure. The extent to which gas reactions are also involved is discussed controversially in the literature [6]. 
The present work, as a contribution to answering this question, traces the release of gas during reaction sintering by means of mass-spectrometric analysis.

\section{Experiments}

Phase formation in the Ti-Al system is traced regarding the thermal effects by means of DSC measurements (DSC 404, Netzsch, argon 5.0).

Specimen expansion during reaction sintering of TiAl is characterized by dilatometer measurements (dilatometer 402E, Netzsch, argon 5.0).

The simultaneous measurement of enthalpy change due to phase formation and of gas release as a function of temperature is done in a combination appliance consisting of an apparatus for simultaneous thermal analysis, STA 409, with a skimmer coupling appliance (Netzsch) and a quadrupole mass spectrometer QMG 420 (Balzers). The measurement takes place unter flowing helium, grade 5.0.

The experiments were performed on extruded specimens of titanium and aluminium powders of a medium grain size of $150 \mu \mathrm{m}$ and with an oxygen content of c. $3000 \mathrm{ppm}$. For this work, two compositions were selected: Ti25Al75 and Ti50Al50. We thank Dr Dahms and Dr Wang of GKSS Research Centre Geesthacht GmbH for letting us have the specimens.

\section{Results}

\subsection{Phase formation in the Ti-Al system}

Based on earlier investigations [3-5], the results of the DSC experiments shown in Fig. 1 can be summarized as follows:

- Regardless of the composition of the initial mixture, $\mathrm{TiAl}_{3}$ is formed first, while energy is released (exothermic process).

- This formation of TiAl3 occurs at $\mathrm{T}<600^{\circ} \mathrm{C}$ through solid phase diffusion (prevailing in case of low heating-up rates).

- At the melting point of aluminium, the rest of the aluminium melts. Within a few minntes the molten mass reacts with the hitherto unreacted titanium, forming $\mathrm{TiAl}_{3}$ (at high heating-up rates, but not exclusively).

- Only with high Al contents (e.g. Ti25AL 75) and high heating-up rates (e.g. $20 \mathrm{~K} / \mathrm{min}$ ) can a short-time endothermic melting effect be observed.

- At temperatures $>700^{\circ} \mathrm{C}$ Tiso $\mathrm{Al}_{50}$ undergoes one more phase transformation, primarily compounded TiAl 3 and Ti forming TiAl on the basis of solid phase diffusion. This process cannot be resolved in the DSC curves because of the small amounts of energy involved.

- The dependence of phase formation on the heating-up rate results from the interrelation between thermodynamics and kinetics.

\subsection{Specimen expansion in the Ti-Al system}

Fig. 2 summarizes the results of earlier measurements of the expansion effects of Ti51Al49 in dependence on the heating-up rate [3]. The degree of specimen expansion grows with increasing aluminium content, with increasing heating-up rate, with increasing portion of transient molten aluminium, with decreasing interphase between aluminium and titanium particles etc. The specimen expansion can reach considerable values. At a heating rate of $5 \mathrm{~K} / \mathrm{min}$, the longitudinal growth in the direction of extrusion amounts to as much as c. $20 \%$ for $\mathrm{Ti}_{25} \mathrm{Al} 75$, and a longitudinal growth of c. $10 \%$ was measured for Ti50 $\mathrm{Al}_{50}$. 


\subsection{Release of gas}

Mass-spectroscopic analysis of the gases released during the heating-up of the Ti-Al specimens results in the detection of hydrogen (mass number $\mathrm{m} 2$ ) and of water (mass number 18). The results are presented in Fig. 3 $\left(\mathrm{Ti}_{25} \mathrm{Al} 75\right.$ ) and Fig. 4 ( $\mathrm{Ti} 50 \mathrm{Al} 50$ ) for heating-up rates of 5 and $20 \mathrm{~K} / \mathrm{min}$, respectively. Apart from the intensity curves for the respective mass numbers, the DTA curve, which was measured simulta-neously, has been drawn in order to document the correlation between phase formation and gas reaction.

Ti25Al75 (Fig. 3)

The formation of $\mathrm{TiAl}_{3}$ (exothermic process), which takes place at low heating-up rates in the solid-phase sector through diffusion processes, does virtually not occur at higher heating-up rates (i.e. $B \geq 20 \mathrm{~K} / \mathrm{min}$ ) because of the short interaction periods [3]. Hence, at about $650^{\circ} \mathrm{C}$ for $\mathrm{B}=20 \mathrm{~K} / \mathrm{min}$ almost all aluminium is molten (endothermal process). Owing to the good wetting and under capillary action the molten mass instantaneousiy spreads across the surface of the titanium particles, where it forms the intermetallic phase $\mathrm{TiAl}_{3}$ within a few minutes (exothermal process). When all of the aluminium has reacted with the titanium available according to the TiAl3 composition, this process closes and the DTA curve runs back to the basis line.

Mass spectrometry establishes that hydrogen (mass number 2) is released when the intermetallic phase $\mathrm{TiAl}_{3}$ is formed, i.e. when aluminium reacts with titanium at temperatures above $700^{\circ} \mathrm{C}$. When all titanium has been consumed the phase formation comes to an end, as does the release of hydrogen.

Water (mass number 18) is generated parallel to the production of hydrogen; the respective intensity curve, too, returns to the initial level between 800 and $850^{\circ} \mathrm{C}$.

Ti50Al50 (Fig. 4)

Whereas in case of low heating-up rates, diffusion-controlled $\mathrm{TiAl}_{3}$ phase formation at the contact surfaces between titanium and aluminium particles takes place well under $600^{\circ} \mathrm{C}(1,2)$, it begins just short off the melting temperature of aluminium according to the course of the DTA curve with $\mathrm{K}=20 \mathrm{~K} / \mathrm{min}$. When aluminium is molten it reacts with the titanium surface it has additionally wetted, forming $\mathrm{TiAl} 3$. The

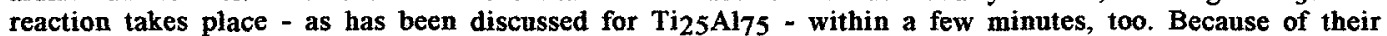
nominal composition these specimens contain less aluminium than $\mathrm{Ti}_{25 \mathrm{Al}} \mathrm{75}$, and because of the higher portion of titanium there are more contact surfaces between both components where intermetallic phase is formed. That is why just the exothermal phase formation enthalpy of TiAl3 formation is recorded; an endothermal aluminium melting effect is not detectable any longer. Apart from that, unreacted titanium is left which forms TiAl due to diffusion interaction with the TiAl3 layers not before the temperature has risen further. This process is not detectable in the DTA-curves due to the small amounts of energy per temperature and time interval.

The accompanying mass spectrometer curve for hydrogen again indicates the release of hydrogen for the TiAl $_{3}$ phase formation sector. So titanium obviously reacts with aluminium, releasing attached hydrogen; this process, however, begins under $650^{\circ} \mathrm{C}$. As less $\mathrm{TiAl}_{3}$ is formed here due to the smaller portion of aluminium, the amount of released hydrogen, too, is smaller than for the $\mathrm{Ti}_{25} \mathrm{Al} 75$ composition shown in Fig. 3. The titanium left over from Ti50Also first retains its attached hydrogen and does not release it before the target phase TiAl is formed through diffusion at the phase contact surface between $\mathrm{Ti}$ and $\mathrm{TiAl} 3$ in case of a further increase of temperature. Hence, a measurable hydrogen concentration is detected at higher temperatures, too; the hydrogen curve as a whole becomes wider and does not return to the basis line within the measured temperature interval.

The generation of water (mass number 18) in turn is related to temperature in the same way as is the release of hydrogen, i.e. it is observable at c. $50 \mathrm{~K}$ below the values for the Ti25Al75 composition, which is richer in alumininm. In this case, water is generated not only in the temperature range of $\mathrm{TiAl}_{3}$ formation but can also be detected at higher temperatures, where the diffusion-controlled phase reaction between $\mathrm{Ti}$ and $\mathrm{TiAl} 3$ results in the formation of TiAl, i.e. the remaining titanium keeps forming intermetallic phase, releasing hydrogen.

When assessing these curves one must take into consideration that the measured intensities of hydrogen and water in the Ti50 Al50 composition are lower in absolute terms due to the smaller amount of generated TiAl3 (as compared with $\mathrm{Ti}_{25} \mathrm{Al} 75$ ), which gives rise to greater measuring incertainties (among others in the water 
curve). This also applies to experiments with low heating-up rates, for the amount of gas released per time unit is smaller here than in an experiment with a higher heating-up rate.

\section{Discussion of results}

Regardless of the composition of the initial material, reaction sintering of titanium and aluminium particles invariably produces $\mathrm{TiAl}_{3}$ first. $\mathrm{TiAl}_{3}$ phase formation is accompanied by the release of hydrogen. The more aluminium the mixture contains, the more hydrogen is released. The hydrogen is originally attached to the titanium and becomes volatile during phase formation. The portion is the higher, the more titanium is consumed for the formation of $\mathrm{TiAl}_{3}$. In the case of $\mathrm{Ti} 25 \mathrm{Al} 75$ all the hydrogen originally fixed is released. With the Ti50Al50 mixture, which contains less aluminium, the primary TiAl3 phase formation does only consume the portion $\mathrm{Ti}_{17} \mathrm{Al}_{50}$ (i.e. less hydrogen is formed), the remaining 33 at.\% of $\mathrm{Ti}$ are only reacted at higher temperatures during phase transformation into TiAl. That is why hydrogen is detected here at higher temperatures as well. The fact that the water and hydrogen curves begin at the same temperature suggests that part of the very active hydrogen reacts with oxygen contained in the material (e.g. reduction of existing oxidic impurities). More experiments will consolidate and bear out this working hypothesis.

The water thus produced must leak from the structure at relatively high temperatures within a very short time, causing additional irregularities and loosening of the structure which largely contribute to the swelling and expansion of the specimens.

What is remarkable when correlating the thermal effect (phase formation) with the release of hydrogen and gaseous water is the fact that there is a temperature difference between the respective maximum values. For example, the temperature/time difference between DTA peak and maximum gas release is c. $40 \mathrm{~K}$ (i.e. 2 min) at a heating rate of $20 \mathrm{~K} / \mathrm{min}$ and c. $20 \mathrm{~K}$ (i.e. $4 \mathrm{~min}$ ) at a heating rate of $5 \mathrm{~K} / \mathrm{min}$. Comparative measurements have shown that in the apparatus used the time from gas release ( $i . e$. start of transportation of the volatile component off the specimen surface by the carrier gas helium) to recording in the mass spectrometer is in the second range, thus as a rule being negligibly small as compared with all other time effects. So there is a total duration of the reaction process including gas formation on the one hand and gas transportation to the specimen surface on the other hand amounting to c. $2 \ldots 4$ min (the maximum transport distance being about $1 \mathrm{~mm}$ for the used specimen geometry of ca. $4 \mathrm{~mm} \varnothing \times 2 \mathrm{~mm}$ ).

Starting from the assumption that gas formation and phase formation are simultaneous processes, the speed of gas transportation within the specimen is estimated to be about $5 \ldots 10 \mu \mathrm{m} / \mathrm{s}$.

In absolute terms, the biggest amount of hydrogen and water is released in $\mathrm{Ti}_{25} \mathrm{Al}_{75}$ during the formation of TiAl3. That is why the correlation of the intensity of the hydrogen and water curves with regard to ascent and drop of both components is well observable there. The width of the DTA effect (representative for the phase formation process in the whole volume) and the width of the gas release process (intensity curves $m 2$ and $\mathrm{m} \mathrm{18}$ ) are nearly the same; at a heating rate of $20 \mathrm{~K} / \mathrm{min}$, phase formation and gas release last for about $7 \mathrm{~min}$, at $5 \mathrm{~K} / \mathrm{min}$ both effects close about $15 \mathrm{~min}$. from the start (however, with a time difference of 2 or 4 min., respectively).

Things are different for Ti50Al50. The period of $\mathrm{TiAl}_{3}$ phase formation becomes shorter while the gas release lasts for a markedly longer period due to the continuing phase transformation into TiAl.

\section{Technological conclasions}

Investigation of gas reactions during reaction sintering of titanium aluminides have revealed that the formation of gaseous water as a result of $\mathrm{TiAl}_{3}$ phase formation is the critical subprocess. Because of the disadvantageous influence on the specimen structure (additional swelling and expansion), ways must be found to reduce water production. Minimizing the content of oxidic impurities is certainly the most effective method, however, its application is limited. Also, the use of titanium powders with low contents of hydrogen would be preferable with regard to water release. Moreover, high heating-up rates should be avoided because they make for the production of relatively large amounts of water within a short time (high portion of transient molten aluminium being the reason for high velocity of phase formation). The increase of particle contact surfaces by deploying smaller particles, by particle deformation (e.g. rolling) and other suitable forms of treatment can improve the situation (larger proportion of slow phase formation in the solid phase zone). The modification of temperature-time-profiles, too, offers good prospects (e.g. change of heating rate, additional isothermal phases)[3]. 


\section{Acknowledgement}

We thank Dr Dahms (GKSS Research Centre Geesthacht GmbH) for making available the specimens and for his consolidating and critical discussion.

\section{References}

[1] Dahms, M.: Mater. Sci. Eng. A Al10 (1989) L5-L8.

[2] Shibue, K., Kim, M.-S., Kumagi, M.: "Microstructure Study of Ti- 47.3 at.\% Al 1.7 at.\% Mn Intermetallic Compound Fabrictaed by Reactive Sintering", in: Proc. Int. Symp. on Intermetallic Compounds, O. Izumi (ed), The Japan Institute of Metals, Sendai, Japan (1991), 833-838.

[3] Dahms, M., Leitner, G., Poeßnecker, W., Schultrich, S., Schmelzer, F.: "Pore formation during reactive sintering of extruded titanium-aluminium powder mixtures", Z. f. Metallkunde 84 (1993) 5, 351-7.

[4]Leitner, G., Dahms, M., PoeBnecker, W., Wildhagen, B.: "Reactive sintering of Titanium aluminides" in: Proceedings of the Inter national Conference on PM Aerospace Materials 1991, paper 18, Lausanne, ed. by MPR Publishing Services Ltd., Shrewsbury, England, 1992.

[5] Leitner, G., Dahms, M., Schultrich, S.: "Sintering behaviour of titanium aluminides", in: Proceedings of the 8th International Conference on Powder Metallurgy in the CSFR, Vol. 2, p. 243-252, Piestany/CSFR, Oct. 1992

[6] Penkava, J.B.: "Untersuchung der pulvermetallischen Bildung und der Eigenschaften der intermetallischen Phasen LiAl und TiAl", Dr.-Ing. Thesis, TU Clausthal, (1988). 

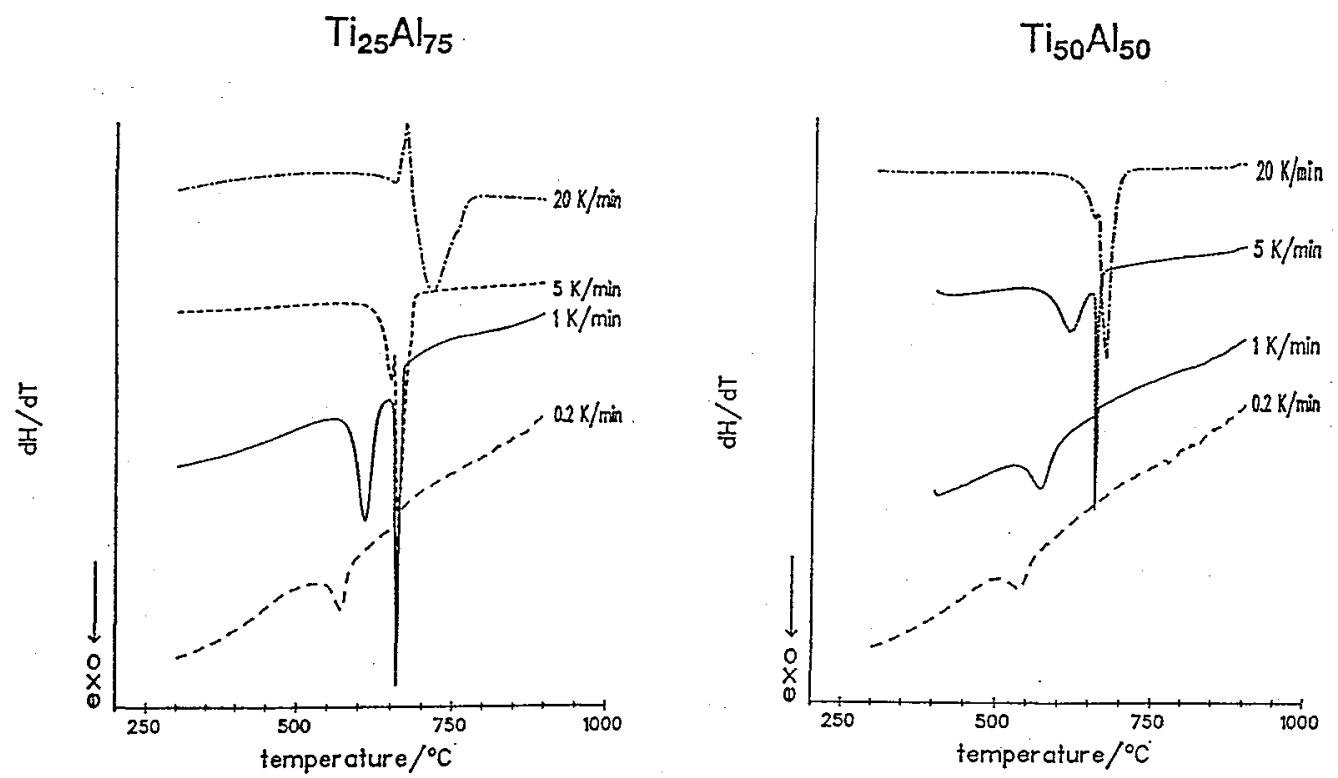

Fig. 1: Phase formation for $\mathrm{Ti}_{25} \mathrm{Al}_{75}$ and $\mathrm{Ti}_{50} \mathrm{Al}_{50}$ with different heating-up rates [5]

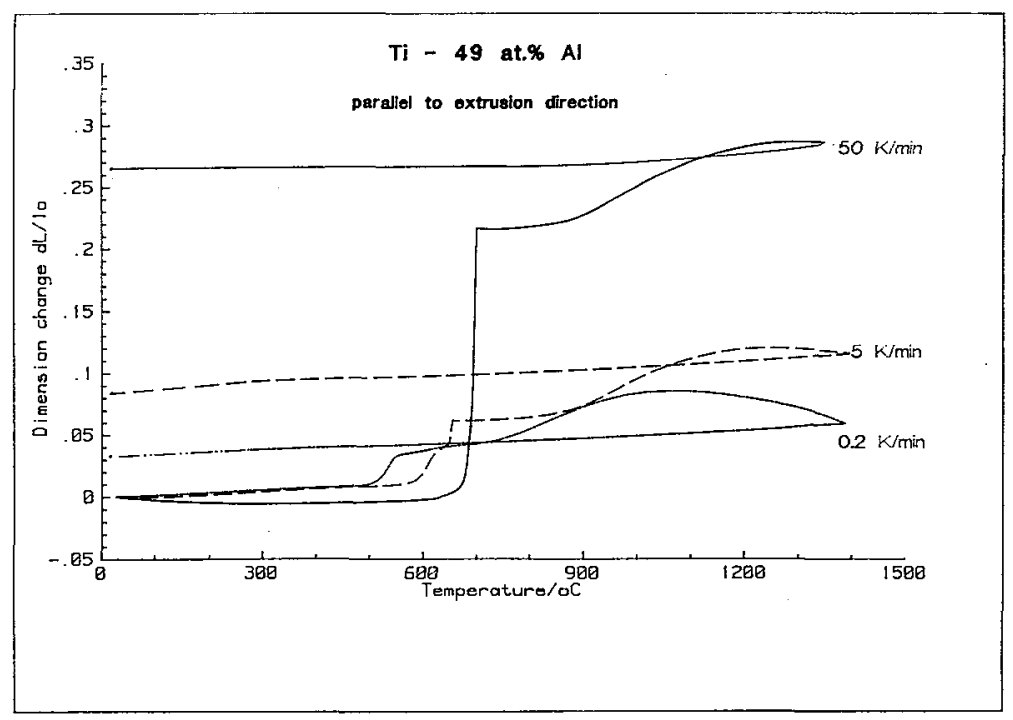

Fig. 2: Longitudinal growth of $\mathrm{Ti}_{51} \mathrm{Al}_{49}$ (in the direction of extrusion) at different heating-up rates [3]. 

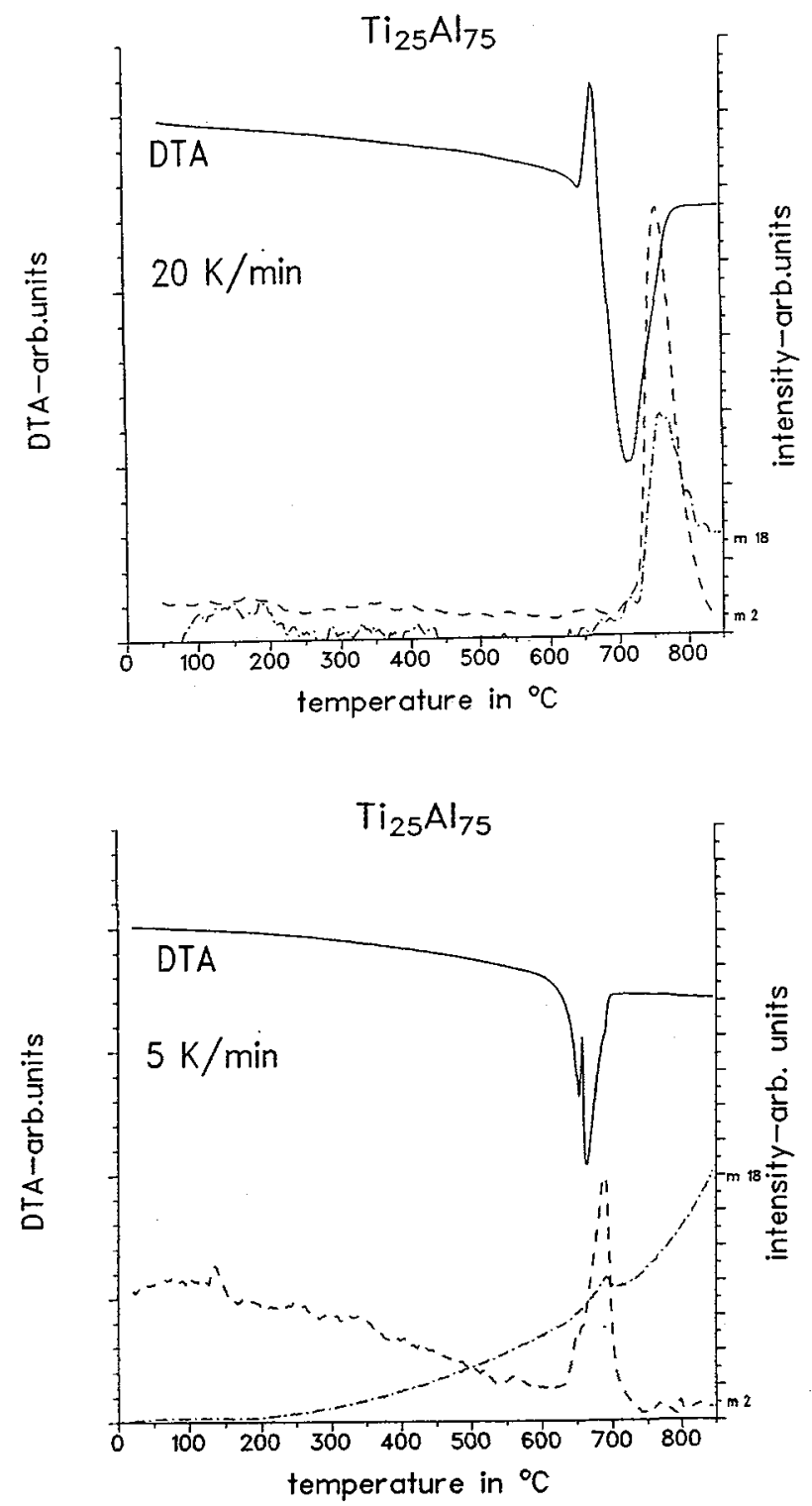

Fig. 3:Release of gas in Ti25Al75 during TiAl3 phase formation (DTA curve) for heating-up rates of 20 $\mathrm{K} / \mathrm{min}$ and $5 \mathrm{~K} / \mathrm{min}$ m2 - hydrogen m18 - water 

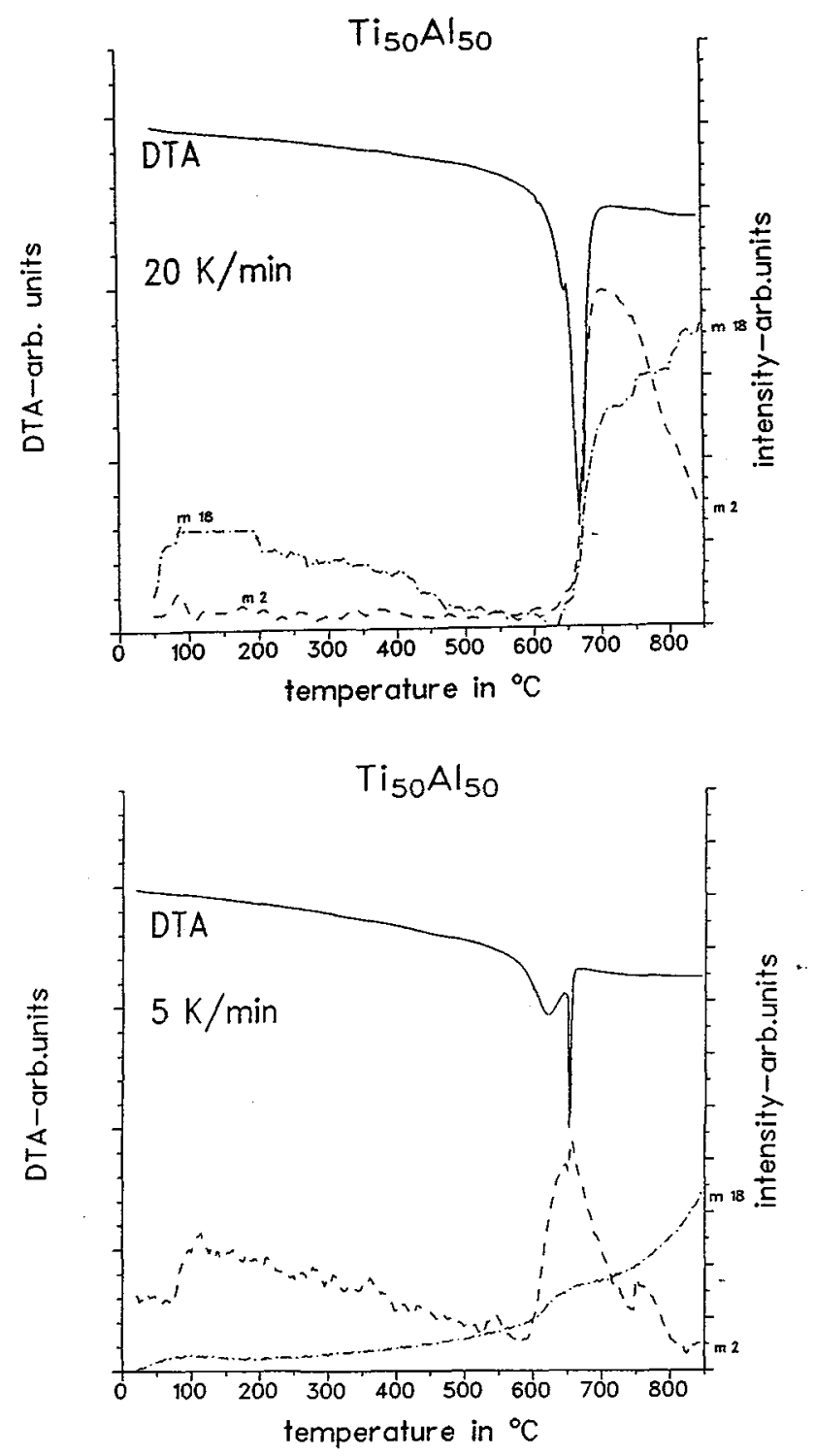

Fig. 4: Release of gas in TisoAl 50 during phase formation for heating-up rates of $20 \mathrm{~K} / \mathrm{min}$ and $5 \mathrm{~K} / \mathrm{min}$. m2 - hydrogen m18 - water 